\title{
CRITÉRIOS DE QUALIDADE PARA O LIVRO DIDÁTICO DE HISTÓRIA NOS ESTADOS UNIDOS (1984-2014)
}

ITAMAR FREITAS

Universidade Federal de Sergipe (UFS)

\section{RESUMO}

Este artigo explora a ideia de "bom livro didático de história" nos Estados Unidos da América - EUA, mediante o exame dos critérios de avaliação, produzidos por oito instituições, de caráter público e privado, entre os anos 1984 e 2014. Conclui-se que uma verdadeira vulgata foi instituída nos últimos 30 anos em torno de exigências relativas aos saberes teóricos e práticos a ensinar, ao alinhamento aos currículos estaduais, ao emprego do método crítico, difusão dos direitos humanos, e aplicação de design útil. Apesar da vulgata, os especialistas afirmam que os livros de história copiam uns aos outros e estão distantes de alguns consensos produzidos pela historiografia acadêmica.

PALAVRAS-CHAVE: Livro Didático de História; Avaliação; Critério de qualidade.

\begin{abstract}
This essay explores the idea of "good history textbook" in United States of America - USA, examining the criteria of evaluation, produced by eight institutions, public and private, between 1984-2014. We concluded that a true vulgate was established in the last 30 years about the knowledge of requirements for theoretical and practical teaching, the alignment curriculum to state, employment of the critical method, dissemination of human rights, and application of useful design. Despite the vulgate, experts say the history textbooks copy each other and are far from consensus produced by some academic historiography.
\end{abstract}

KEYWORDS: History Textbook; Evaluation; Quality. 
Já faz parte do senso comum dos historiadores a afirmação de que o livro ideal somente existe (e, obviamente, porque ideal) na cabeça do usuário, sobretudo na do professor. A tese é incômoda, por seu tom relativista. Contudo, sugere caminhos menos pantanosos para a construção, avaliação e usos dos livros didáticos de história. Como isso é possível?

A resposta antropológica é simples e bem antiga: a diversidade é um estoque de soluções à disposição de todos. E nós, que lidamos cotidianamente com o livro didático, podemos experimentar essa fortuna ao examinar os vários critérios arbitrados em diferentes contextos e culturas. É o que fazemos neste texto, partindo de uma amostra da literatura especializada sobre a avaliação de livros didáticos nos Estados Unidos - EUA. Quem determina os princípios de qualidade? Quais são os critérios empregados no julgamento das obras? Onde se encontram (ou se desviam) os indicadores do bom livro didático de história nos EUA?

\section{Um conhecido e polêmico objeto de pesquisa}

As perguntas que anunciamos acima, evidentemente, não inauguram uma linha de investigação. Elas resultam de um longo esforço acumulado de pesquisadores de vários países que, sobretudo nos últimos 30 anos, têm se dedicado a recortar e examinar o livro didático sob os mais diversos ângulos e interesses. Sem a ilógica pretensão de inventariar essas iniciativas, podemos, entretanto, afirmar que os principais lugares de produção, com os quais os pesquisadores brasileiros têm dialogado, são a França, a Espanha, a Inglaterra e, em menor escala a Argentina, Canadá, Alemanha e os Estados Unidos ${ }^{1}$.

Uma breve incursão pelos trabalhos de alguns dos maiores especialistas e, consequentemente, formadores de opinião na área, como Circe Bittencourt ${ }^{2}$, Kazumi Munakata ${ }^{3}$, Décio Gatti Júnior ${ }^{4}$, Arlete Gasparello ${ }^{5}$, Margarida M. D.

\footnotetext{
${ }^{1}$ Sobre os lugares de produção e a natureza da pesquisa a respeito de livros didáticos de história no Brasil, ver a dissertação de Kênia Hilda Moreira (2006). Ela afirma que entre 1980 e 2005 foram defendidas 5 teses e 41 dissertações, 10 em programas de História e 32 em Educação e 5 em outras áreas. A maioria (30) foi produzida na região Sudeste e o restante (16) disperso pelo Brasil.

${ }^{2}$ BITTENCOURT, Circe. Livro didático e conhecimento histórico: uma História do saber escolar. São Paulo, 1993. Tese (Doutorado em História) - Departamento da Faculdade de Filosofia, Letras e Ciências Humanas da Universidade de São Paulo.

${ }^{3}$ MUNAKATA, Kazumi. História que os livros didáticos contam, depois que acabou a ditadura no Brasil. In: FREITAS, Marcos Cezar de (org.). Historiografia brasileira em perspectiva. São Paulo: Contexto, 1998. pp. 271-296.

${ }^{4}$ GATTI JÚNIOR, Décio. A Escrita Escolar da História: livro didático e ensino no Brasil (19701990). Bauru: Edusc; Uberlândia: Edufu, 2004.

${ }^{5}$ GASPARELLO, Arlete Medeiros. Construtores de identidades: a pedagogia da nação nos livros didáticos da escola secundária brasileira. São Paulo: Iglu, 2004.
} 
Oliveira, Inês Istamatto ${ }^{6}$, Maria Auxiliadora Schmidt ${ }^{7}$, Flávia Caimi, Maria Carolina Bovério Galzerani, João Batista Gonçalves Bueno ${ }^{8}$ e Luis Fernando Cerri $^{9}$ vai revelar a contribuição de historicistas renovados (Jörn Rusen), teóricos críticos do currículo (Michel Apple e Ivor Godson), historiadores das disciplinas escolares (André Chervel e Jean Hebrard), e experts no inventário e história comparada de livros didáticos em escala nacional (Cuesta Fernandes e Gonzalo Amézola) e transcontinental (Gabriela Ossenbach, Agustín Escolano, Rafael Valls, Christan Laville e Allan Chopin). No fundo desses referenciais estão poderosas instituições de pesquisa sobre livros didáticos como o "Georg Eckert Institut" em Braunshweig, o "Centre National de la Recherche Scientifique" (CNRS), em Paris, o Centro de Investigación de los Manuales Escolares (MANES), em Madrid, o banco de dados "Livros Escolares Brasileiros: 18102005" (LIVRES), em São Paulo, e os grupos de pesquisa que se empenham nos estudos chamados de "educação histórica", em diferentes vertentes, na Universidade de Laval e na Universidade de Londres.

Hoje, com base nesses autores - e apesar dos diferentes interesses e bases epistemológicas - os pesquisadores brasileiros parecem caminhar sob algumas certezas provisórias: o livro didático de história, sobretudo, (1) é mercadoria; (2) é portador de ideologia; (3) é estratégico para o Estado; e (4) não pode veicular todo o resultado da pesquisa acadêmica. Como desdobramento, os estudiosos vão além da denúncia sobre a manipulação e a interessada desatualização dos conteúdos, que podem representar "desvios" na formação de crianças e adolescentes - tendência dominante, pelo menos, até meados da década de 1990, como bem afirmaram Bárbara Freitag, Wanderley da Costa e Valéria Mota ${ }^{10}$.

É nesse contexto acadêmico que a opção pelas questões acima se insere. Avançar na pesquisa sobre o livro didático significa, então, e também, aprofundar o nosso conhecimento sobre os critérios de qualidade anunciados por diferentes agentes envolvidos com a produção, avaliação e usos do livro didático de história em diferentes culturas. Em que medida eles diferem? Existem similaridades entre sociedades de padrões de comportamento diferenciados? O que justifica essas permanências e singularidades? Em que

6 OLIVEIRA, Margarida Maria Dias de; STAMATTO, Maria Inês (Org.). O livro didático de História: políticas educacionais, pesquisas e ensino. Natal: Editora da UFRN, 2007.

7 SCHMIDT, Maria Auxiliadora; GARCIA, Tania Braga; VALLS, R. (Orgs.). Didática, História e Manuais escolares: contextos ibero-americanos. 1a. ed. Ijui: Editora da UNIJUI, 2013.

${ }^{8}$ CAIMI, Flávia. O que sabemos (e o que não sabemos) sobre o livro didático de história: estado do conhecimento, tendências e perspectivas. In: Maria Carolina Bovério Galzerani; João Batista Gonçalves Bueno; Arnaldo Pinto Júnior. (Org.). Paisagens da Pesquisa Contemporânea sobre o Livro Didático de História. Jundiaí: Paco Editorial, 2013, v. 1, pp. 35-52.

${ }^{9}$ CERRI, Luis Fernando. Análise e avaliacão de livros didáticos de $1^{\mathrm{a}}$ a $4^{\mathrm{a}}$ séries do $1^{\mathrm{o}}$ grau no Programa Nacional do Livro Didático do MEC - 1998. In: II Simpósio do Laboratório de Ensino de História, 1997, Londrina - PR. II Simpósio do Laboratório de Ensino de História. Anais...Londrina - PR: s.c.p., 1997. p. 5.

${ }^{10}$ FREITAG, Bárbara; COSTA, Wanderely F. da; MOTTA, Valéria R. O livro didático em questão. 3 ed. São Paulo: Cortez, 1997. 
medida esse tipo de pesquisa pode nos auxiliar a pensar os problemas sobre o livro didático de história para além da denúncia ou da "historiografia da falta"? Esse tipo de ação nos obriga - por mais anticientífico que possa parecer a sentença - a não adotar um posicionamento teórico a priori sobre os sentidos de critérios ou os modos de atribuir valor aos mesmos.

\section{Cada cabeça, uma sentença}

O que é um livro didático? É um artefato que veicula textos escritos, imagéticos e/ou sonoros, organizados de modo linear ou hipertextual, disponíveis em suporte papel, plástico policarbonato, microchips de silício ou ondas eletromagnéticas, cuja principal função é auxiliar aos alunos, professores, pais ou responsáveis no processo de aquisição de conhecimento e habilidades relativas e circunscritas a determinada disciplina escolar.

Para muitos pesquisadores, o sentido de livro didático tanto se expandiu que é melhor, agora, falar em "material didático". Somente a título de exemplo, Ministére de L'Éducation Nationale, de l'Enseignement Supérieur et de la Recherche da França compartilha uma dezena de materiais didáticos eletrônicos em seu site ${ }^{11}$ e a antiga National Association of State Textbook Administrators ${ }^{12}$ listou 48 tipos de instructional materials, disponíveis no mercado americano em formatos impresso, digital, fechado e aberto. Para o público brasileiro, entretanto, são raros os pesquisadores que defendem a Wikipedia (on-line aberto), por exemplo, como material didático. Juliana Bastos, entusiasta do emprego da ferramenta no ensino da história romana, afirma que a "precariedade" de muitas informações históricas e o "receio de plágio" têm fundamentado a "tendência generalizada entre docentes, do ensino básico ou superior, de se proibir ou ao menos coibir o uso da enciclopédia como fonte de

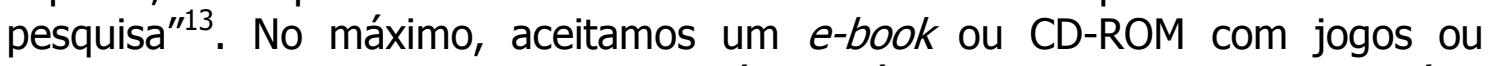
hipertextos que reproduzam os conteúdos clássicos dos manuais de história para os alunos. Assim, permaneçamos no âmbito deste texto com o termo "livro didático".

Sobre tal artefato, arriscamos afirmar que, em qualquer lugar do mundo, os critérios para medir a sua qualidade são extraídos de diferentes princípios,

\footnotetext{
${ }^{11}$ FRANCE. Ministére de L'Éducation Nationale, de l'Enseignement Supérieur et de la Recherche. Enseigner avec le numérique. [Paris], MEN. Disponivel em: http://eduscol.education.fr/numerique/dossier/archives/ressources-en-ligne. Consultado em 9 jul. 2017.

12 NATIONAL ASSOCIATION OF STATE TEXTBOOK ADMINISTRATORS. Common criteria for new forms of instructional materials support Commom Core State Standads (CCSS). ACTS/NASTA, 2011. Disponível em: http://nasta.org/2011_ACTSNASTA_CommonCoreSession_Handout.pdf. Capturado em 10 abr. 2014.

${ }^{13}$ MARQUES, Juliana Bastos. Trabalhando com a história romana na Wikipédia: uma experiência em conhecimento colaborativo na universidade. Revista História Hoje, v. 2, n. 3, pp. 329-346, 2010. O assunto já gerou dissertação de mestrado, citada pela própria autora: VIEIRA, Marli Fátima Vick. $A$ Wikipédia é confiável? Credibilidade, utilização de uma enciclopédia online no ambiente escolar. Dissertação (Mestrado em Educação) - Univale. Santa Catarina, 2008. Disponível em: http://siaibib01.univali.br/pdf/Marli\%20Fatima\%20Vick\%20Vieira.pdf; Acesso em: 28 ago. 2012.
} 
originados de diferentes interesses e das peculiaridades de cada sistema escolar (que também refletem os desejos de variados sujeitos individuais pessoais e coletivos). Na França, divergem sobre conhecimentos pedagógicos, suporte/design, conhecimentos históricos, apuro linguístico e valores da república nacional o Syndicat Nacional de l'Édition - $\mathrm{SNE}^{14}$, autores de livros didáticos ${ }^{15}$, a Association National des Conseillers pédagogiques ANCP $^{16}$, os inspetores gerais de ensino (IGEN) ${ }^{17}$ e a Association for Research on Textbooks and Educational Media (IARTEN) ${ }^{18}$. Na Índia, o forte das disputas sobre critérios de qualidade, entre autoridades nacionais e locais - além do apuro informacional e da simplicidade da linguagem - é o controle ideológico (socialismo vs. nacionalismo, secularismo vs. religiosidade) ${ }^{19}$. Na Polônia pós 1989, disputas entre autores, editores e políticos puseram questões estéticas (preto e branco vs. policromia), liberdade de pensamento e inculcação de princípios democráticos na pauta de disputas pela elaboração dos critérios ${ }^{20}$. Para os países africanos de língua francesa, os critérios sugeridos por especialistas enfatizam a adequação dos livros de história a um currículo mínimo comum sobre a experiência africana, a atualização dos conhecimentos sobre história do continente, a apresentação de estratégias pedagógicas renovadas e incorporação das novas tecnologias da informação e da comunicação $^{21}$. No Japão é o Ministério da Educação, Cultura, Esportes, Ciência e Tecnologia (MEXT) quem pauta os critérios: obediência ao currículo estatal, respeito aos estágios cognitivos do aluno, imparcialidade em termos de religião,

14 SYNDICAT NATIONAL DE I'ÉDITION. Standards de I'EPUB 3. Sdt. Groupe Normes \& Standards/SNE, 20 jun. 2013.2 Disponível http://www.sne.fr/img/pdf/SNE/Numerique/AtelierNS-26juin2013.pdf. Capturado em 18 abr. 2014.

${ }_{15}$ SAVOIR LIVRE. Conseils aux enseignants. Disponível em: http://www.savoirlivre.com/indexpht. Consultado em 17 abr. 2014.

${ }^{16}$ ASSOCIATION NATIONALE DES CONSEILLERS PÉDAGOGIQUES. Une aide au choix du manuel scolaire. In: Guide des Conseillers Pédagogiques de circonscription. ANCP. [Paris]: sd., p. $28 . \quad$ Disponível em: https://webtice.acguyane.fr/CAFIPEMF/IMG/pdf/pdf_guide_du_cpc_complet.pdf. Capturado em 17 abr. 2014.

17 BORNE, Dominique. Le manuel scolaire. [Paris]: Inspection Génerale de l'Éducation Nationale/Ministère de l'Éducation Nationale, de la Recherche et de la Technologie, jun. 1998.

${ }^{18}$ CHOPPIN, Alain. Le Manuel scolaire, une fausse evidence historique. Histoire de I'Éducation, [Paris], n. 117, pp. 6-56, 2008. Disponível em: HTTP://histoire-education.revues.org/565. Capturado em 10 abr. 2014. BRUILLARD, Éric. Ressources pédagogiques et enseignement scolaire - Proposition de Standards. Oslo: Association for Research on Textbooks and Educational Media (IARTEM), 2013. Disponível em: http://www.iartem.org. Capturado em 18 abr. 2014.

${ }^{19}$ BANERJEE, Basabi Khan. West Bengal history textbooks and de Indian textbook controversy. Internationale Schulbuchforschung, n. 29, pp. 355-374, 2007. BHATTACHARYA, Neeladri. Teaching history in schools: the politics of textbooks in India. History Workshop Journal, n. 67, pp. 99-100, 2009.

20 PARKER, Christine S. History education reform in post-communist Poland, 1989-1999: historical and contemporary effects on educational transition. Ohio, 2003. Dissertation (Doctorate of Philosophy) - Graduate School, Ohio State University.

${ }^{21}$ KIPRÉ, Pierre. Inventaire critique des manuels scolaires d'histoire en usage dans les pays d'Afrique francofone. Paris: Unesco, 2002. 
ideologia ou crença, precisão factual, purismo da língua etc. Mas as disputas entre esquerda e direita (típicas da Guerra Fria), em torno da inclusão dos conteúdos "dolorosos", por exemplo ("a ação nipônica na cidade de Nanjing ou a instalação de casas de prostituição compulsória pelos militares ao longo dos anos 1930 e 1940"), também interferem no sentido de qualidade do livro didático $^{22}$. No Canadá e no Brasil, também é o Ministério da Educação quem prescreve os critérios de qualidade. Para o primeiro, indicadores referem-se à forma (logicidade da organização e durabilidade material) e ao conteúdo (correção da informação, adequação do conhecimento às faixas etárias, presença de referências às novas tecnologias, saúde e segurança dos alunos, responsabilidade com o meio ambiente e respeito às potencialidades cognitivas dos alunos, presença de estratégias de avaliação e ausência de preconceitos raciais, etnoculturais, religiosos, regionais, ou idade) ${ }^{23}$. No Brasil, além das questões materiais, há indicadores de cumprimento da legislação inclusiva, no que diz respeito, por exemplo à presença da experiência de africanos, afrodescendentes e indígenas ${ }^{24}$.

Em todos esses lugares, pesquisadores também manifestam interesses e produzem os seus critérios de qualidade ou seja, os indicadores que devem limitar a produção de um bom livro didático de história. Essas propostas oscilam entre fundamentos multidisciplinares (a psicologia da aprendizagem de Lev $\mathrm{S}$. Vygotsky, a linguística de M. Bakhtin, a semiótica de Barthes, a análise do discurso de Althusser) e disciplinares (a teoria da história de J. Rüsen, a metódica de P. Lee), forma (materialidade e organização das informações) ${ }^{25}$ e

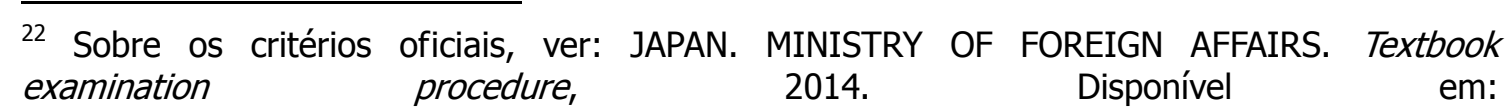
http://www.mofa.go.jp/policy/education/textbooks/overview-3.html. Consultado em 8 jul. 2014. Sobre as disputas pelas memórias da guerra e o Ministério da Educação, entre esquerda e direita, ver: KONDO, Takahiro. Pertinence de I'opposition des historiens japonais au controle du minitère de l'Éducation sur les manuels scolaires. In: SABURET, Jean-François; SONOYAMA, Daisuke. Liberté, inégalité, individualité: le Japon e la France ao miroir de l'éducation. Paris: CNRS, 2008. pp. 136-147. SILVA, Marina Magalhães Barreto Leite. A guerra aprendida na escola: a transmissão de memórias japonesas no tempo presente. Revista Eletrônica do Tempo Presente, n. 1, v. 1, jan./mar. $2014 . \quad$ Disponível em: http://www.tempopresente.org/index.php?option=com_content\&view=article\&id=5897:aguerra-aprendida-na-escola-a-transmissao-de-memorias-japonesas-no-tempopresente\&catid=95:edicao-do-mes-de-marco-2014\&Itemid=229. Consultado em 8 jul. 2014.

${ }^{23}$ CANADA. Ministry of Education. Guidelines for approval of textbooks. Ontario: ME, 2006. Disponível em: http://edu.gov.on.ca. Consultado em: 8 jul. 2014.

${ }^{24}$ Sobre os critérios de qualidade produzidos pelo estado, ao longo do século XX, ver: Historiografia didática e prescrições estatais sobre conteúdos históricos em nível nacional (1938-2012). Revista Territórios e Fronteiras, Cuiabá, v. 6, n. 3, pp. 7-24, 2013. Sobre os indicadores de qualidade das duas últimas décadas para os livros de história do ensino fundamental e do ensino médio, ver, respectivamente: NAUSS, Paulo. Por onde anda a história na atualidade da escola: ensino médio, livros didáticos e ensino de história. In: ROCHA, Helenice; MAGALHÃES, Marcelo; GONTIJO, Rebeca. A escrita da história escolar. memória e historiografia. Rio de Janeiro: Fundação Getúlio Vargas, 2009. pp. 293-308. GATTI JÚNIOR, Décio. Estado, currículo e livro didático de história no Brasil (1988/2007). In: OLIVEIRA, Margarida Maria Dias de; STAMATTO, Maria Inês Sucupira. O livro didático de história: políticas educacionais, pesquisa e ensino. Natal: Ed. UFRN, 2007, pp. 29-31.

${ }_{25}$ Para uma amostra dessa variação, flagrada na América Latina e nos países escandinavos, ver, principalmente: GALVALISE, Celia Fabiana. "Sobre enfoques, instrumentos y critérios para la 
conteúdo (mensagem, ideologia, natureza do conhecimento histórico etc.). No Brasil, dois desses autores são bastante conhecidos: o alemão Jörn Rüsen ${ }^{26}$ e 0 espanhol Rafael Valls ${ }^{27}$. O primeiro pensa o livro ideal a partir da sua teoria da história, ou seja, a partir dos elementos que atribuem racionalidade à ciência da história (metódica e orientação da vida prática). Por esses princípios, um bom livro didático de história deve auxiliar a desenvolver, principalmente, as habilidades de percepção, interpretação e orientação histórica. Assim, respectivamente, os critérios de qualidade estão na capacidade de o livro apresentar (1) atratividade, pluralidade e pluriperspectividade da experiência histórica; (2) conhecimento produzido metodicamente; (3) estímulo à formação de juízos e referências ao presente. O segundo autor, Rafael Valls, pensa a qualidade a partir de elementos da teoria da história e da psicologia cognitiva. Seus critérios, portanto, incluem: (1) a capacidade de o livro de história executar adequada transposição didática; (2) servir à vida prática do leitor; (3) explicitar e cumprir determinado modelo didático; e (4) ampliar as possibilidades cognitivas do aluno.

São, portanto, múltiplos os conjuntos de critérios de qualidade apresentados para o ensino de história, seja entre os pesquisadores do ensino, seja entre os demais agentes envolvidos com o artefato - professores, alunos, gestores, jornalistas, ativistas, parlamentares, autores e editores. Integrandoos, como faz Valls, ou singularizando-os, como faz Rüsen, apenas experimentamos alternativas para resolver problemas pontuais de determinada realidade escolar. Contudo, quem se envolve com a formulação de políticas públicas de larga escala, não pode, sob pena de fracasso imediato, adotar de modo puro esse ou aquele critério produzido por um especialista, ainda que a intensão seja a mais meritória - a formação de sujeitos capacitados a ler criticamente uma notícia veiculada por um telejornal, um anúncio publicitário ou um programa partidário. Nenhuma teoria dá conta do real em toda a sua plenitude (nenhum conjunto de critérios provoca, quando em uso, choques de "gestão" que modifiquem os modos de os alunos refletirem sobre o seu entorno de modo autônomo). É por isso que a proposta deste texto não é encontrar modelos que substituam as práticas de julgamento da qualidade do livro de

revisión de la calidad de los libros escolares" e LESTER, Luis Ajagan. Evaluando las evaluaciones. In: CHILE. MINISTERIO DE EDUCACIÓN. Primer Seminario Internacional de Textos Escolares - SITE 2006. Santiago: Governo do Chile; Unesco, 2007. pp. 307-331. Para o mesmo caso no Brasil e na França, ver, respectivamente: MUNAKATA, Kazumi. Livro didático e formação de professor são incompatíveis? (pp. 89-94, v. 1) e HEBRARD, Jean. O livro didático de ontem ao amanhã (pp. 25-30, v. 5). In: BRASIL. MINISTÉRIO DA EDUCAÇÃO. Congresso Brasileiro de Qualidade da Educação: formação de professores. Brasília: MEC/SEF, 2002.

26 RÜSEN, Jörn. O livro didático ideal. In: SCHMIDT, Maria Auxiliadora; BARCA, Isabel; MARTINS, Estevão de Rezende (orgs). Jörn Rüsen e o ensino de história. Curitiba: Editora da UFPR, 2010, pp. 109-127.

${ }^{27}$ VALLS, Rafael. Los textos escolares de historia: uma propuesta de análisis y valoración. In: DHIGECS - SEMINARI DE PROFESSORAT DE GEOGRAFIA I HISTÒRIA. Els llibres de text i l'ensenyament de la Història: Record d'en Jordi Burguera Gómez. Barcelona: Departament de Didàctica de les Ciències Socials, 2008, pp. 63-72. 
história no Brasil, mas conhecer, no sentido mais simplório da palavra, como determinadas culturas enfrentam esse problema e, a partir dos impasses e das soluções gestadas nesses lugares, alimentar a reflexão sobre as questões referentes à qualidade do nosso livro didático, tão conhecidas na literatura nativa, principalmente nos últimos dez anos. É por isso também que este texto se encerra com perguntas. Por isso, enfim, que iniciamos o "conhecimento" dos critérios $^{28}$ por um país que se transformou, durante o século $\mathrm{XX}$, em um dos maiores laboratórios de (e para a) pesquisa educacional no Ocidente, inclusive sobre o livro didático de história. Contudo, por cruzamentos históricos que não podemos aqui discutir, os EUA são, hoje, um grande desconhecido para a esmagadora maioria dos pesquisadores brasileiros dedicados ao ensino de história.

\section{A qualidade do livro didático de história nos EUA}

Nos EUA, dentro do período abarcado por este trabalho, o livro didático foi objeto de polêmicas em torno das histórias a ensinar. O debate, fortalecido na década de 1980 - conhecido como "History wars" ${ }^{29}$-, foi registrado por historiadores e teóricos do currículo. Entre os historiadores, Gary Nash, Charlotte Crabtree, Ross Dunn e Linda Symcox se destacaram. A maior preocupação desse grupo foi com a denúncia referente à guinada à direita da política estadunidense, que interferiu diretamente na seleção dos conhecimentos históricos escolares, reforçando os mitos fundadores da nação (via legislativo, executivo e grandes corporações da era Ronald Reagan), em detrimento dos temas relacionados à ampliação dos direitos civis, majoritários à época, entre os historiadores acadêmicos. As guerras de história legitimavam o entendimento de que o currículo era mesmo "um território de disputas", na feliz acepção de Michael Apple, o estudioso do currículo estadunidense, inclusive citado por Lind Symcox. Mas Apple fez mais que oferecer um bordão. Para ele, o livro didático é definido mediante lutas de interesses de classe, raça, gênero, grupos religiosos e grupos econômicos. Foi um dos primeiros a revelar as bases para a criação de critérios de qualidade dos livros didáticos (em vigor, naquela época), os seus defeitos, as limitações positivas e negativas das ideologias e, principalmente, a concentração do mercado editorial dos didáticos em pequenos e privilegiados grupos ${ }^{30}$. Foi também um dos primeiros, nesse período, a apontar a examinar a relação entre a qualidade do livro didático e o caráter descentralizado das políticas educacionais nos EUA.

\footnotetext{
${ }^{28}$ Em outros trabalhos (em curso), realizamos o mesmo exame a partir da experiência da África do Sul, İ́ndia e França.

29 As mesmas questões foram discutidas simultaneamente, em lugares como Argentina, Austrália, Canadá, Alemanha, Japão, África do Sul, Rússia, Reino Unido. Ver sobre o assunto: TAYLOR, Tony; Guyver, Robert. History wars \& classroom: global perpectives. Charlote: Information Age publishing, 2011.

${ }^{30}$ APPLE, Michael w. Textbook publishing: the political and economic influences. Theory into Pratice, v. 28, n. 4, pp. 282-287.
} 
Essa independência de cada ente federado, para gerir os assuntos da educação, implica em prescrições, procedimentos e resultados muito diferentes para a avaliação, aquisição e uso dos livros didáticos. Os pesquisadores estadunidenses costumam usar "territórios abertos", territórios fechados, estados "rígidos", "moderadamente restritivos", "flexíveis", entre outras metáforas, para caracterizar a política de seleção e adoção de livros didáticos em seu país ${ }^{31}$. Também esboçam uma tendência: entre o século XIX e o XX (a primeira legislação data de 1818, na Filadélfia), a política de adoção migrou da liberdade individual à prescrição estatal. A partir da década de 1960, a dicotomia sofisticou-se. Pela primeira vez, verifica-se 0 interesse dos historiadores pelo embate entre a adoção de livros didáticos em nível estadual e a adoção em nível local ${ }^{32}$.

Para ilustrar essa variação, informamos que, há uma década, 29 dos 50 governos estaduais concediam aos responsáveis oficiais pelos distritos, ao diretor da escola ou ao professor de história o direito de escolha. Nos demais, três tipos de gerenciamento destacavam-se: a seleção estatal (o Estado escolhe os títulos), a recomendação estatal mediante listas (o Estado lista títulos e deixa que os professores escolham entre os indicados) e a combinação dos dois processos $^{33}$.

Dessas três modalidades resultavam, portanto, situações como a do Estado do Tennessee, onde quase todos os doze livros da lista eram aceitos, e do Alabama, que adotava apenas um livro, em 2007. Independentemente do modo, contudo, os livros são avaliados, sugeridos ou adotados, em sua grande maioria, por um comitê - State Textbook Boards - formado por advogados, pais, professores, historiadores, entre outros, que, em geral, trabalham voluntariamente ${ }^{34}$.

Por aqui, já percebemos quantos atores entram em cena. Em primeiro lugar, o Estado, que indica parte ou a totalidade dos membros dos comitês. Além disso, impõe a adoção dos seus programas curriculares como um dos critérios de qualidade e tenta controlar os custos e as práticas do mercado editorial. Essas são as principais metas dos entes federados, ao adotarem

${ }^{31}$ DURRANCE, V.R. Public textbook selection in forty-eight states. Phi Delta Kappan, v. 33, n. 5, pp. 262-266, 1952. SEWALL, Gilbert T. American history textbooks: an assessment of quality (A Report of the Educational Excellence Network). New York, 1987. Estados "fechados", "moderados" e "abertos" significam, em geral, uma espécie de gradação de lugares que avaliam ou que deixam aos professores a tarefa de avaliar os livros didáticos ou, mais importante, que impõe todo o currículo, parte do currículo ou nenhum currículo de maneira compulsória como base para a construção dos livros didáticos.

32 WATT, Michael G. Research on the textbook selection process in the United States of America. IARTEM e-Journal, v. 2, n. 1, pp. 2-21, 2009. (Association for Research on Textbooks and Educational Media). p. 3; p. 19.

${ }^{33}$ SEWALL, op. cit., p. 20; Gilbert T. American history textbooks: an assessment of quality (A Report of the Educational Excellence Network). New York, 1987. THOMAS B. FORDHAM INSTITUTE. The mad, mad world of textbook adoption. Washington: Thomas B. Fordham Institute, 2004. p. 3, pp. 19-21.

${ }^{34}$ LOEWEN, James W. Lies my teacher told me: everything your American history textbook got wrong. 3 ed. New York: The New Press, [2077]. p. 308. 
procedimentos de avaliação ${ }^{35}$. Mas há outros envolvidos que irrigam os referidos interesses estatais. Grupos empresariais, movimentos que congregam ateus, religiosos, negros, mulheres, gays, hispânicos, indígenas, ou instituições que representam ativistas de direta e de esquerda, historiadores universitários, entre outros. Cada um, ao seu modo, idealiza o livro didático e, consequentemente, os parâmetros para construí-lo e julgá-lo.

A lista de desejos é enorme. Que deve fazer, então, o brasileiro que se interessa pelo "grande irmão", com o objetivo de melhor conhecer o seu próprio país? Compreender é a tarefa. Compreender que, em regime democrático, o desejável torna-se o "certo", "academicamente correto" e "politicamente correto", apenas, na arena política. Vence o melhor argumento ou a mais forte pressão argumentada.

Mas quem se ocupa da produção e avaliação de livros didáticos de história não pode restringir-se à compreensão, tem que agir, fazer escolhas - e boa escolha faz quem olha para os lados, para frente e, principalmente, para trás. Vejamos algumas tentativas de difusão de critérios de qualidade para 0 livro didático de história nos EUA.

\section{Agentes e lugares de produção da qualidade}

Nos últimos 30 anos, foram muitas as iniciativas de regrar a produção do bom livro didático de história ${ }^{36}$. $\mathrm{Na}$ impossibilidade de cobri-las extensamente, selecionamos nove lugares de produção de critérios de qualidade. Buscamos esforços de organizações não governamentais e também propostas estatais.

A primeira delas foi produzida pela People For The American Way - PAW $(1986)^{37}$, à época dirigida por Antony T. Podesta. A empreitada teve o apoio da Organization of American Historians (OAH), que era liderada pelo professor de história da Universidade de Indiana, Jooah Hoff-Wilson. A PAW viabilizou, então, a análise dos mais importantes livros didáticos de História dos EUA que circulavam no Texas e em outras partes do país, em 1985. Nesse empreendimento, 31 livros, adotados nos grades [séries ou anos letivos, para o Brasil] 8 e 10, foram analisados. O alvo das resenhas eram os profissionais das

\footnotetext{
${ }^{35}$ WATT, op. cit, p. 20.Michael G. Research on the textbook selection process in the United States of America. IARTEM e-Journal, v. 2, n. 1, pp. 2-21, 2009. (Association for Research on Textbooks and Educational Media).

${ }^{36} \mathrm{Um}$ bom exemplo dessa variedade está na pesquisa realizada por profissionais do "Search Labs, Microsoft Research, Montain View", da Califórnia. Partindo da literatura especializada, eles elegem três critérios de qualidade para o livro didático, inclusive de história: (1) "foco" - cada seção deve expor/explicar poucos conceitos; (2) "unidade" - cada conceito deve frequentar apenas uma seção e deve ser muito bem exposto/explicado; e (3) "sequencialidade" - os conceitos devem ser discutidos de forma sequencial. Um por um, sendo o próximo conceito muito mais significativo que o primeiro. (AGRAWAL, R; CHAKRABORTY, S.; GOLLAPUDI, S; KANNAN, A; KENTHAPADI, K. $2012 . \quad$ Disponível em: http://research.microsoft.com/pubs/163747/qualityOfTextbooksAnEmpiricalStudydev12.pdf?origin=publication_detail. Consultado em 5 mar. 2014.

37 DAVIS JÚNIOR, et. al. Looking at history: a review of major US. History textbooks. Washington: People for the American Way, 1986.
} 
escolas, as autoridades locais da política educacional e também os editores de livros didáticos. Os critérios foram elaborados, provavelmente, por um grupo de críticos que atuavam como professores de história e de educação, na escola básica e em universidades ${ }^{38}$, e eram liderados pelo professor de currículo e ensino da Universidade do Texas, O. L. Davis Jr.

A segunda iniciativa, mais abrangente, resultou da análise de 11 dos mais adotados livros do país nos três níveis do ensino básico: elementary, high school, e secondary school. Foi pensada e acolhida no Teatchers College da Columbia University, dentro da Educational Excellence Network e financiado pelo United States Department of Education. À frente estavam Diane Ravitch, Janice Riddel, John Donovan, conhecidos pesquisadores do ensino de história, auxiliados, entre outros, pelo expert Paul Gagnon. O relatório foi organizado por Gilbert T. Sewall ${ }^{39}$, que depois se tornaria um dos maiores especialistas na matéria.

Outra mostra vem do American Textbook Council $^{40}$ que não apenas desejava a melhoria da qualidade dos livros didáticos, mas também se preocupava com a qualidade da crítica exercida pelos indivíduos ou comitês no ato da escolha. Por isso, além de pôr em análise os livros mais presentes nas salas de aula dos estados da Califórnia, Indiana, North Carolina, Florida e New York (três para a elementary e 12 para a secondary school), o relatório, também organizado por Sewall ${ }^{41}$, fornece um checklist para uso dos professores. A avaliação foi conduzida por historiadores, especialistas em livros didáticos, professores da escola básica e assessorada por Walter A. MacDougall, Paul Gagnon, Robert Hagopian, Peter Gagnon e Roger W. Smith. A Universidade da Califórnia (Santa Bárbara) acolheu o grupo, e as fundações John M. Olin e Bodman financiaram o projeto.

Quatro anos depois, em 2004, Thomas B. Fordham Institute ${ }^{42}$ investiu na melhoria da qualidade dos livros didáticos de história. Dessa vez, o objeto foram os doze livros de maior circulação no país, produzidos pelas maiores empresas do ramo nos EUA, dos quais seis livros de história dos EUA e seis de história mundial. O relatório, apresentado por Chester E. Finn Jr e introduzido por Diane Ravitch, também fornece recomendações e esclarece os critérios de avaliação. O objetivo do trabalho, empreendido por nove membros (entre historiadores, professores de história e de educação, dos ensinos básico e superior $)^{43}$, foi também indicar as fragilidades e pontos fortes dos livros didáticos e melhorar a capacidade de julgamento dos usuários e compradores dos seus livros.

\footnotetext{
${ }^{38}$ Lyn M. Burlbaw, Maria Garza-Lubeck, Alfred Moss e Gerald Ponder.

${ }^{39}$ SEWALL, op. cit., p. 20.

${ }^{40}$ SEWALL, 2000, op. cit.

${ }^{41}$ SEWALL, Gilbert T. History textbooks at the new century. s.dt: American Textbook Counsil, 2000.

${ }^{42}$ RAVITCH, Diane. A consumer's guide to high school history textbooks. Washington: Thomas

B. Fordham Institute, 2004.

43 Morton Keller, Jeffrey Mirel, John Pyne, Edward J. Renhan Jr, Lucien Ellington, Marc A. Epstein, Margaret C. Jacob, Walter Russel Mead e Theodore K. Rabb.
} 
Recentemente, outra instituição não governamental (que reúne especialistas em materiais didáticos e, sobretudo, gestores de instituições públicas estaduais, responsáveis pela avaliação, compra e/ou adoção de livros didáticos em todos os membros da federação), também divulgou os seus renovados critérios. A State Instructional Materials Review Association (SIMRA) corresponde à antiga National Association of State Textbook Administrators (NASTA). Juntamente com a Association of American Publishers (APP) ${ }^{44}$ e a Book Manufacturers' Institute $(B M I)^{45}$, que reúnem, respectivamente, representantes dos editores e dos fabricantes de livros didáticos, a SIMRA constitui a Advisory Commission on Textbook Specifications (ACTS), uma septuagenária produtora de critérios (gerais) de qualidade para os materiais didáticos, que iniciou seus trabalhos adotando os parâmetros do Texas, em sua versão atual. A ACTS ocupa-se, predominantemente, de padrões de design, formato, composição, impressão, qualidade do papel e preços dos livros didáticos ${ }^{46}$.

As últimas iniciativas aqui citadas foram colhidas nos três estados mais influentes na modelização dos livros didáticos do país: a Califórnia, Texas e Flórida. Na Califórnia, duas diretrizes fornecem as bases para os critérios de avaliação dos livros didáticos. A primeira é a legislação "social" de âmbito estadual. A segunda é o currículo oficial, estabelecido pelo executivo do estado. Ambos - Curriculum Frameworks e Standards for evaluating e o Instructional materials for social content ${ }^{47}$, produzidos pelo California State Board of Education $^{48}$, prescrevem os critérios do bom livro didático de história.

No Texas, o executivo estadual, por intermédio do State Board of Education (SBOE), também indica os comitês revisores dos currículos. Os comitês são constituídos por educadores de renome, pais de alunos, empresários. Sobre eles recai a responsabilidade de revisar os currículos Texas Essential Knowledge and Skills (TEKS) ${ }^{49}$ - em períodos que podem durar quatro $\operatorname{anos}^{50}$. Os comissionados, entretanto, não têm a palavra final. 0

\footnotetext{
${ }^{44} \mathrm{http}: / /$ www.publishers.org/.

${ }^{45}$ http://www.bmibook.org/.

46 BOOK MANUFACTURERS' INSTITUTE. ACTS History: a brief history of the advisory commission on textbook specifications (ACTS). Book Manufacturers' Institute. Disponível em: http://www.bmibook.org/acts/acts-history/. Capturado em 14 abr. 2014.

${ }^{47}$ CALIFORNIA DEPARTMENT OF EDUCATION. History-Social Science framework for California Public Schools - kindergarten through grade twelve. Sacramento: History-Social Science Curriculum Framework and Criteria Committee, 2005. [Atualizado em 2009]. CALIFORNIA STATE BOARD OF EDUCATION. Standards for evaluating instructional materials for social content. Sacramento: Curriculum Frameworks and Instructional Resources Division/California Department of Education, 2013.

$48 \mathrm{http}: / /$ www.cde.ca.gov/be/.

49 TEXAS EDUCATION AGENCY. Texas Essential Knowledge and Skills for Social Studies [Kindergarten, Elementary school, Middle school, and High school]. Austin: State Board of Education, 2010. Disponível em: http://www.tea.state.tx.us. Capturado em: 12 fev. 2014.

50 Texas Education Code. Austin: Texas Education Agency. 2011. § 66.3. Disponível em: http://www.statutes.legis.state.tx.us/?link=ED. Capturado em 2 jun. 2014. TEXAS EDUCATION AGENCY. Texas Essential Knowledge and Skills Overview - Publisher orientation meeting Proclamation 2015. Austin: State Board of Education, 2013. Disponível em: http://www.tea.state.tx.us. Capturado em: 10 abr. 2014. TEXAS EDUCATION AGENCY.
} 
processo inclui revisões e contra-revisões entre o comitê e o SBOE, que podem alterar o trabalho do primeiro. Nos livros didáticos, por fim, diferentemente da Califórnia, apenas $50 \%$ dos conhecimentos e habilidades prescritas pelo TEKS são exigidos, além das orientações relativas ao suporte/design, inscritas no Manufacturing Standards and Specifications for Textbooks ${ }^{51}$.

Na Flórida, os distritos escolares, individualmente ou em consórcios, são responsáveis pela avaliação dos livros didáticos. Sobre eles também recai a responsabilidade pelos processos de compra, estabelecimento dos ciclos de revisão e a prescrição dos deveres e das qualidades do pessoal responsável pela crítica do material didático ${ }^{52}$. Os critérios, entretanto, são apresentados pelo governo estadual e prescrevem o alinhamento do material didático ao Social Studies Standards (SSS) do Next Generation Sunshine State Standards (NGSSS), adotado em 2008. Além disso, contemplam temáticas comuns a outros processos de avaliação, como a inclusão de valores e a exigência de precisão na apresentação das informações históricas ${ }^{53}$.

Conhecidos os produtores, a natureza e um pouco do interesse de cada iniciativa, vejamos, por fim, o que predominou e o que rareia em termos de critérios de qualidade para o livro didático de história nos limites desta amostra e nas últimas três décadas.

\section{A vulgata do bom livro}

O rol de critérios varia em termos de princípios e até nas dimensões e níveis de detalhamento. No período anterior à nossa amostra, algumas propostas estatais, como a de Iowa [1983], concentravam-se nos aspectos gráficos, desprezando os conteúdos substantivos ${ }^{54}$ ou a qualidade da escrita ${ }^{55}$.

Proclamation 2015. Austin: State Board of Education, 2013. Disponível em: http://www.tea.state.tx.us. Capturado em 10 abr. 2014.

51 STATE INSTRUCTIONAL MATERIALS REVIEW ASSOCIATION (SIMIRA). Manufacturing Standards and Specifications for Textbooks. 2012. Disponível em: http://www.bmibook.org/wpcontent/uploads/MSST-Webinar-2012.pdf.

52 FLORIDA DEPARTMENT OF EDUCATION. Memorandum (Florida Instructional Materials Changes Resulting from Senate Bill 1388). [Tallahssee]: State Board of Education, 6, set. 2013a. Disponível em: http://info.fldoe.org/docushare/dsweb/Get/Document-6817/dps-2013-110.pdf. Capturado em 10 abr. 2014, pp. 1-2.

${ }^{53}$ FLORIDA DEPARTMENT OF EDUCATION. Florida online instructional materials review training. [Tallahssee]: State Board of Education, 2013b. Disponível em: http://www.fldoe.org/bii/instruct_mat/. Capturado em 10 abr. 2014.

${ }^{54}$ Conteúdos substantivos representam, numa acepção mais larga, os atos, sentimentos e pensamentos humanos registrados por intermédio da escrita da história. Numa acepção mais restrita, na linguagem partilhada pelos historiadores, conteúdos substantivos são os acontecimentos (nos quais estão envolvidos os sentimentos e pensamentos). Como há grande polêmica em torno do sentido e da relevância do acontecimento para a escrita da história, esclarecemos que, neste texto, acontecimento é o elemento constituinte da narrativa. Ele conserva a ideia de ocorrência - fenômeno linguisticamente expresso por um verbo ou 
Outras, ao contrário, qualificavam os livros didáticos a partir da sua capacidade de incutir nos alunos a valorização e o respeito à experiência de indivíduos e grupos, independentemente da sua condição sexual, racial, religiosa ou étnica; em outros termos, bom livro didático seria aquele que incluísse os personagens, ideias e acontecimentos relacionados às "minorias" estadunidenses ${ }^{56}$.

Dos anos 1980 em diante, tempo das grandes iniciativas de caráter nacional, no sentido de reestabelecer o alto padrão de qualidade das escolas estadunidenses ${ }^{57}$, tempo também dos mais calorosos debates de conteúdos de história a ensinar ${ }^{58}$, a variação se manteve, em termos de princípios e quantidade de itens.

A diversidade está, em primeiro lugar, nos princípios ou (na ausência de termos mais precisos) no primeiro grau hierárquico da taxonomia. A Tabela 1 demonstra a distribuição dos critérios de qualidade por grupos de princípios e, à primeira vista, podemos já concluir que as iniciativas elegem de três a seis princípios ao longo das últimas três décadas.

No conjunto, percebemos que o conhecimento pedagógico é o mais reivindicado. Contudo, no exame caso a caso, vemos que ele só predomina no SIMRA (50\%) e no TBFI (64\%). Os conteúdos meta-históricos ${ }^{59}$, por seu turno, predominam no PAW/OAH (63\%) e no TC/CU (33\%). Os valores são majoritários na Califórnia (50\%) e o conjunto Suporte/design domina os critérios da ATC (47\%). Há também os casos de divisão equitativa de princípios, como o Texas que distribui igualmente (33\% para cada) os critérios entre conteúdos meta-históricos, conteúdos substantivos e o suporte/design, e a

substantivo que denota ação (evento). Ele é fruto da "antítese dos tempos verbais" - pretérito perfeito e pretérito imperfeito, por exemplo. $\mathrm{O}$ acontecimento "corresponde ao que Aristóteles chamava de mutação de sorte - metabolé - na sua teoria formal da armação da intriga". RICOEUR, Paul. Tempo e narrativa. São Paulo: Papirus, 1994. v. 1, p. 320 . Ver também: RICOEUR, Paul. Évenement et sens. In: Raisons pratiques. Paris: n. 2, pp. 41-45, 1991, p. 43.0 acontecimento riceuriano, ou o conteúdo substantivo da escrita da historiografia, sobretudo didática, é constituído, por ações, motivações, nome dos sujeitos, data cronológica e data tópica (cenário da ação).

${ }^{55}$ CHENEY, Lyne V. Textbooks. In: Tyrannical machines - $A$ report in educational practices gone wrong and our Best hopes for setting them right. Washington: National Endowment for the Humanities, 1990. pp. 13-14.

${ }^{56}$ NATIONAL EDUCATION ASSOCIATION. Checklist for selecting and evaluating U.S. history textbooks. Washington: National Education Association, 1973.

57 PATRICK, John J. The Bradley Commission in the context of 1980s: curriculum reform in the social studies. The History Teacher, v. 23, n. 1, pp. 36-48, nov. 1989.

${ }^{58}$ NASH, Gary B.; CRABTREE, Charlotte; DUNN, Ross E. New strategies to raise. NASH, Gary B.; CRABTREE, Charlotte; DUNN, Ross E. History on trial: culture wars and the teaching of the past. New York: Alfred A. Knopf, 1999, pp. 110-114.

59 Os conteúdos meta-históricos são aqueles que estão por trás ou "além" (meta) dos conteúdos substantivos (ver nota 50). São as habilidades das quais o historiador lança mão para fazer o registro da experiência humana. Dentro da acepção metódica do século XIX, na Alemanha e na França, tais habilidades representam etapas no método crítico: identificar, localizar, classificar, ler, criticar, interpretar (fontes históricas), argumentar e construir sínteses históricas. No glossário contemporâneo, elas representam as "operações processuais da pesquisa históricas", que são abonamentos da metódica do século XIX. Sobre esse conjunto de operações ("heurística", "crítica" e "interpretação"), ver: RÜSEN, Jörn. As operações processuais. In: Reconstrução do passado - Teoria da história II - os princípios da pesquisa histórica. Brasília: Editora da UnB, 2007, pp. 104-133. 
Flórida, que atribui aos conteúdos substantivos e aos valores idêntica importância (30\%).

É necessário, porém, esclarecer que os números da Tabela 1 indicam apenas a representatividade do grupo de princípios atribuída por cada estado em número de critérios de qualidade. Não é possível afirmar, por exemplo, que - alinhamento aos conteúdos substantivos (ideias, personagens, acontecimentos) é menos forte na Califórnia que no Texas. As ponderações (os "pesos") de cada critério e de cada princípio não são explicitadas na documentação consultada, devido à variação de processos de seleção já informados no primeiro tópico deste texto. No entanto, os números relativos indicam que há uma progressiva inclusão de princípios. Primeiro aparecem os pedagógicos, os de metodologia da história, conteúdos substantivos, os valores e os gráficos. Na última década, são acrescentadas, ainda que de forma residual, as questões relativas à saúde e à enfática inclusão da experiência das minorias.

Tabela 1 - Distribuição dos critérios, segundo classes de qualidade

\begin{tabular}{|c|c|c|c|c|c|c|c|c|c|c|c|c|}
\hline Ano & Iniciativas & CP & CS & CM & S/D & V & CL & A & S & M & NC & Total \\
\hline 1986 & PAW/OAH & $13 \%$ & $13 \%$ & $63 \%$ & $13 \%$ & & & & & & & $100 \%$ \\
\hline 1987 & TC/CU & $8 \%$ & $8 \%$ & $33 \%$ & $33 \%$ & $8 \%$ & $8 \%$ & & & & & $100 \%$ \\
\hline 2000 & ATC & $12 \%$ & $29 \%$ & $6 \%$ & $41 \%$ & $6 \%$ & $6 \%$ & & & & & $100 \%$ \\
\hline 2004 & TBFI & $64 \%$ & $8 \%$ & $17 \%$ & $6 \%$ & $3 \%$ & $3 \%$ & & & & & $100 \%$ \\
\hline 2005 & Califórnia & $17 \%$ & $11 \%$ & & & $50 \%$ & & $6 \%$ & $11 \%$ & & $6 \%$ & $100 \%$ \\
\hline 2008 & Florida & $20 \%$ & $30 \%$ & $20 \%$ & & $30 \%$ & & & & & & $100 \%$ \\
\hline 2009 & Texas & & $33 \%$ & $33 \%$ & $33 \%$ & & & & & & & $100 \%$ \\
\hline 2011 & SIMRA & $50 \%$ & $15 \%$ & $5 \%$ & & $10 \%$ & $5 \%$ & $5 \%$ & & $10 \%$ & & $100 \%$ \\
\hline
\end{tabular}

Legenda: CP - Conteúdos Pedagógicos; CS - Conteúdos Substantivos; CM - Conteúdos Metahistóricos; S/D - Suporte/Design; V - FALTOU; CL - Conteúdos Linguísticos; A - Acessibilidade; S - Saúde; M - Novas Mídias; NC - Não Classificado.

\subsection{A importância dos saberes teóricos e práticos do ensinar}

Abandonando os números relativos e examinando, detalhadamente, cada critério, veremos algumas aproximações entre as iniciativas recolhidas como amostra. A mais significativa delas é a semelhança entre os critérios aqui chamados de "pedagógicos". A sua adoção, como pudemos acompanhar pela Tabela 1 , não é homogênea. A maioria dos elementos dessa rubrica está concentrada no $\operatorname{TBFI}^{60}$ e no SIMRA ${ }^{61}$. O que dizem esses critérios?

${ }^{60}$ THOMAS B. FORDHAM INSTITUTE. The mad, mad world of textbook adoption. Washington: Thomas B. Fordham Institute, 2004.

${ }^{61}$ STATE INSTRUCTIONAL MATERIALS REVIEW ASSOCIATION (SIMRA), op. cit. 
Lendo-os como atributos positivos, podemos concluir que bom livro didático de história é aquele que amplia os conhecimentos do aluno e do professor, apresenta atividades variadas para o aluno e para o professor, possui coerência entre os livros do aluno e do professor e mecanismos de progressão das aprendizagens do aluno e docente. Os critérios também primam pelo desenvolvimento das habilidades de problematizar, discutir, analisar, criticar, resolver problemas, elaborar hipóteses, sintetizar e concluir.

Outro grupo de critérios enfatiza a necessidade de o livro didático estimular $\mathrm{o}$ aluno e o professor, em termos de aprendizagem ativa e significativa, e favorecer a formação continuada do docente. Deve ainda, o livro, fornecer estratégias de ensino, avaliação, planejamento, elaboração de currículo. Importante registrar que apenas um critério explora a necessidade de correção e integração da história/estudos sociais com as demais disciplinas, o que, no Brasil, é conhecido como virtude interdisciplinar.

\subsection{Prescrições sobre os conteúdos acontecimentais}

No que diz respeito aos conteúdos substantivos, segundo grupo mais frequente na nossa amostra (o único presente em todas as iniciativas), há residuais diferenças. Obviamente, como a rubrica indica (conteúdos substantivos), já esperávamos que os critérios incluíssem o alinhamento do livro didático ao currículo de história/estudos sociais (Califórnia, Texas e SIMRA). Isso ocorre com ínfimas variações. O Texas e a TBFI exigem a inserção de personagens, eventos, ideias, culturas e períodos da história dos Estados Unidos e da história mundial, enquanto a Flórida prescreve a história dos EUA. Uns são mais genéricos, exigindo a inserção da experiência do político, social, cultural e econômico (TBFI); outros, mais restritivos, tornam obrigatória a presença de documentos como a Declaração de Independência e Constituição dos EUA (Califórnia).

Por outro lado, os critérios reforçam a necessidade do rigor na apresentação dos acontecimentos (Flórida e SIMRA) e na referenciação de fontes e textos historiográficos (TBFI). Mas, há quem demonstre incômodo com a inserção de novos sujeitos e novas dimensões da experiência humana (sinal dos tempos?). São os casos da ATC (2000), que requer sensatez na adoção de novos heróis, que não admite a marginalização das histórias constitucional e econômica, da PAW/OAH (1986) e também da ATC, que não admitem a ausência de elementos da identidade nacional e da contribuição das ideias ocidentais para a sociedade global.

\subsection{0 lugar do método crítico}

Quanto à presença das operações processuais do ofício de historiador, não há divergências. A maioria pede exatidão na apresentação dos conteúdos acontecimentais (datas tópica e cronológica, nome dos sujeitos históricos, correta atribuição de virtudes etc.), o desenvolvimento das habilidades de 
contextualização, análise, síntese, o adequado emprego de fontes primárias e das noções de causa, consequência e mudança.

Os critérios também prescrevem que os livros didáticos não soneguem as controvérsias historiográficas aos alunos e se esforcem para representar 0 passado a partir de múltiplas perspectivas interpretativas. No entanto, apenas um exige que o livro declare uma posição sobre o tema em litígio (TC/CU 1987). Nesse sentido, há flagrante discrepância entre os que proíbem a parcialidade política ou ideológica, o presentismo (anacronismo) e o moralismo (TBFI) e o que valoriza, no livro, o estímulo ao protagonismo do aluno (TC/CU).

\subsection{Incutir valores}

Cabe também ao bom livro didático inculcar determinados valores, fundamentais à formação do cidadão estadunidense. Quais seriam eles?

Observando a Tabela 1, vemos que os valores são referidos em 5 das 8 iniciativas. $E$, aqui, é forçoso registrar a ênfase que a Califórnia concede a essa rubrica (lembramos, novamente, que os números relativos da Tabela 1 não representam "pesos"). É claro que os valores estão embutidos, em vários princípios geradores de critérios, a exemplo dos conteúdos substantivos. Mas, chama a atenção, por um lado, o cuidado da TC/CU e do SIMRA com o perigo de transmissão de ideologias, pelo livro didático e, por outro, o declarado estímulo ao respeito e à valorização da democracia, dos direitos humanos (FBFI), da diversidade de gênero, sexual, de idade, modos de trabalho, etnia, raça, religião, onde o termo "autoestima" do aluno é, várias vezes, empregado.

Nesse quesito, os critérios também contemplam o respeito aos idosos, a importância do conhecimento dos alunos acerca do processo de envelhecimento, a proteção ao meio ambiente, o respeito e a provisão de igualdade de oportunidades para os portadores de necessidades especiais e 0 estímulo ao sentimento de compaixão e de humanidade em relação às pessoas e aos animais.

\subsection{Suporte, design e layout}

A preocupação com os aspectos materiais e gráficos dos livros didáticos está presente já na segunda iniciativa desta amostra. Nesse sentido, os documentos analisados não diferem muito. Todos estão interessados em prover o aluno de um recurso que facilite o desenvolvimento da leitura e realização das atividades, mediante projetos que apresentem clareza e simplicidade, conforto e prazer. Os livros devem ser facilmente manuseáveis (e isso implica em formatos compatíveis e número reduzido de páginas), devem fornecer visão 
geral do conteúdo de forma sintética e lógica e, ainda, articular textos complementares, texto principal, atividades e ilustrações.

A leitura dos critérios desse princípio sugere, claramente, uma ligação entre as formas/texturas do artefato e os saberes acumulados da psicologia educacional, sobretudo quando são citados o interesse e o prazer dos alunos. Mas há um caso em que a preocupação tem caráter mais historiográfico. Ao requisitar como critério a manutenção do texto narrativo principal, é provável que os avaliadores do TC/CU estivessem preocupados com os recentes avanços dos elementos suplementares (ilustrações, tabelas, mapas, gráficos, vinhetas etc.) na mancha, em detrimento do texto escrito, entendido este último como a história em sentido estrito.

Não sabemos se as qualidades da escrita do livro didático podem ser incluídas nesse tópico. Mas a ausência de relações diretas, nos documentos, com as questões pedagógicas, permite-nos situá-las neste espaço. São poucas e dispersas as referências, tanto que podem ser sintetizadas em três exigências: apresentar linguagem realista [não metafórica?] (TC/CU), envolvente (ATC e TBFI) e compatível com o grau de ensino e a matéria (SIMRA).

\subsection{Princípios residuais}

Os últimos princípios (os mais raros) primam pela saúde dos alunos, estimulando o consumo de alimentação saudável, a prática da atividade física, a segurança física e psíquica dos mesmos, quando solicita que o livro didático esclareça sobre os usos e abusos de substâncias perigosas e a prevenção a incêndios (Califórnia). Por fim, os critérios também exigem que o material didático seja acessível a todos, inclusive aos portadores de necessidades especiais (Califórnia e SIMRA).

\section{Conclusões}

Vimos, então, que o bom livro didático de história, nos Estados Unidos, entre 1984 e 2014, vem sendo idealizado por diferentes sujeitos e os critérios produzidos para esse fim variam com os interesses desses atores, que podem ser instituições criadas pelos estados para gerir essa específica política, associações de historiadores, associações de gestores educacionais, conselhos privados de caráter nacional, fundações, rede de pesquisadores universitários, autores e empresários do setor.

Por parte dos estados, há o interesse em controlar os conteúdos, fazendo cumprir a legislação local, e também de regular os preços ou a concorrência. As associações não governamentais, por seu turno, ocupam-se da exatidão no processo de apresentação dos conhecimentos e habilidades, como também e, paradoxalmente, da vigilância ideológica e da doutrinação em termos de princípios democráticos e de cidadania estendida. A maioria delas, 
entretanto, anuncia uma intenção pedagógica: melhorar os níveis de julgamento de pais, professores e especialistas responsáveis pela avaliação e usos do livro didático de história. Os empresários, por fim, os menos citados neste texto, tentam regular as características do suporte e do design, criando um padrão mínimo de qualidade para a indústria estadunidense, reservando, provavelmente, fatias lucrativas do mercado para determinados conglomerados.

Apesar das diferenças de ênfase, no que diz respeito aos princípios e de algumas discrepâncias com relação aos critérios, como escolha dos conteúdos substantivos (antigos heróis ou minorias étnicas? Posicionamento crítico ou imparcialidade ideológica do narrador?), pudemos notar, nos limites desta amostra, que nenhum princípio predominou ao longo do tempo. Mais que isso, nas últimas três décadas, constituiu-se uma verdadeira vulgata que atribui ao bom livro didático de história, qualidades relativas aos saberes teóricos e práticos do ensinar, ao alinhamento aos currículos estaduais, à presença das operações processuais da pesquisa e da escrita da história, aos valores relacionados aos direitos civis, políticos e sociais, ao adequado e produtivo design. Em menor escala e distanciando-se da vulgata, notamos a expansão dos critérios de qualidade para as questões de segurança e saúde individual dos alunos, demonstrando o alinhamento às novas e problemáticas tarefas impostas ao professor, nos últimos 15 ou 20 anos, em várias partes do Ocidente.

Para encerrar, cumpre apresentar uma desconfortável notícia, colhida entre antigos e recentes trabalhos especializados: as diferentes formas de seleção (escolar, distrital, estadual) e de adoção (aberta ou fechada), as sucessivas tentativas de modificar os processos de escolha e as denúncias sobre a má escrita dos autores, por exemplo, não têm interferido, significativamente, na qualidade do livro didático ${ }^{62}$ no que diz respeito, sobretudo, à variação de propostas historiográficas, pedagógicas ou de design. Os livros também continuam "chatos" ${ }^{63}$ e "caros" ${ }^{\prime 64}$. Além disso - a despeito de terem incluído estratégias de gerenciamento da informação e técnicas de autoaprendizagem, avanço verificado nos anos 1990, com relação aos livros dos anos $1980^{65}$-, eles permanecem muito parecidos. As razões, sintetizadas em recentes estudos, dos quais destaco o de James Lowen ${ }^{66}$, são muitas.

\footnotetext{
${ }^{62}$ TYSON, Harriet; WOODWARD, Arthur. Social studies and history textbooks. In: Why students aren't learning very much from textbooks: Publishers won't produce better textbooks until selection committees become more discerning and demanding about quality. Educational Leadership, nov. 1989. pp. 14-17. Association for Supervision and Curriculum Development. WATT, 2009, op. cit., p. 21.

${ }^{63}$ FIN JR, Chester E. The mad, mad world of textbook adoption. Thomas B. Fordham Institute. Washington DC, 2004.

${ }^{64}$ KORNBLITH, Gary; LASSER, Carol. "The truth, the whole truth, and nothing but the truth": writing, producing, and using College-level American History Textbooks. The Journal of American History, v. 91, n. 4, pp. 1380-2, mar. 2005.

${ }^{65}$ WAKEFIELD, John F. $A$ brief history of textbooks: where have we been all these years? Paper presented at the Meeting of the Text and Academic Authors. St. Petersburg: sdt., 1998.

${ }^{66}$ LOEWEN, James W. Lies my teacher told me: everything your American history textbook got wrong. 3 ed. New York: The New Press, [2007].
} 
Em primeiro lugar, os estados de maior população (que prescrevem o alinhamento dos livros aos currículos de história/estudos sociais) modelizam a produção de quase todo o país. Em consequência, os autores escrevem para públicos cada vez mais abrangentes e os conteúdos dos livros de história são ampliados a cada revisão, com o que concorda Alan Brinkley ${ }^{67}$, renomado autor de livros didáticos e professor de história da Columbia University. Há temor entre os editores de retirar algum material, e a tendência é incluir tudo aquilo que uma suposta ausência possa resultar em controvérsias.

Outro problema está na inovação dos layouts. Eles avançam por sobre os textos, algo referido nos critérios que anunciamos há pouco. Há quem concorde com essa denúncia. Mary Norton ${ }^{68}$, autora, entre outros livros, do didático $\mathrm{A}$ people and a nation: a history of the United States (1982), odiava a interrupção da narrativa por boxes e vinhetas. Mas foi Brinley ${ }^{69}$, também pouco entusiasta da reduzida coesão da narrativa principal, quem ofereceu a resposta aos críticos: "Este é o preço que se paga para incluir as mais diferentes visões da história que incorporamos na última geração".

Lowen, contudo, apresenta críticas mais graves. Seja em termos de layouts, seja em termos de conteúdos substantivos, meta-históricos ou pedagógicos, os autores ou editores "copiam" uns aos outros. Quando o tema é a história do tempo presente, a situação beira o escândalo: quase todos os capítulos recentes são escritos por ghostwriters.

Lowen também denuncia o desinteresse dos historiadores acadêmicos pelo gênero. Eles não querem produzir e nem resenhar livros didáticos, ações que contribuiriam para a melhoria desse recurso. Os poucos que escrevem, entretanto, apresentam certa esquizofrenia, resultante, talvez, das disputas mercadológicas: eles pensam diferente, mas se assemelham na escrita didática patriótica, quase norma nos livros didáticos de história. Para esse ponto, Brinkley ${ }^{70}$ também apresenta uma justificativa: como conciliar a posição (que é única) do historiador acadêmico com a necessidade de apresentar visões alternativas acerca dos eventos nos livros didáticos?

Transferindo o foco, dos acadêmicos para os professores da escola básica, Lowen sugere uma saída: não poderiam esses profissionais agir como principais controladores da qualidade, combatendo a síndrome da "cópia", por exemplo? O próprio responde, imediatamente, que não há como isso acontecer, pois significativa parte deles não é formada em história e não gosta de controvérsias, sobretudo porque foram formados dentro da cultura do pensamento único, paradoxalmente, no interior das universidades. Assim, os professores identificam-se bastante com o livro didático de história com o qual trabalham, inclusive com seus erros.

Mas é hora de encerrar este texto e a melhor forma que encontramos é questionando: será que já não nos deparamos com esta situação em outro momento? Temos ou não motivos suficientes para examinar a experiência

\footnotetext{
${ }^{67}$ BRINKLEY, Alan. The challenges and rewards of textbook writing. The Journal of American History, v. 91, n. 4, pp. 1391-7, mar. 2005.

${ }^{68}$ NORTON, Mary Beth. Reflections of a longtime textbook author: or, history revised, revised and revised again. The Journal of American History, v. 91, n. 4, mar. 2005, p. 1384.

${ }^{69}$ BRINKLEY, op. cit., p. 1934.

${ }^{70}$ BRINKLEY, op. cit., p. 1934.
} 
transnacional (olhar para os lados e, principalmente, para trás)? Vocês duvidam que a história do ensino de história tenha alguma função social dentro dos departamentos de história? Que reflexões podem ser deflagradas sobre a realidade brasileira a partir das informações colhidas com os especialistas estadunidenses? Qual seria o melhor caminho para o aperfeiçoamento (isso para quem reclama) da qualidade dos nossos livros didáticos de história? Deveríamos transferir a avaliação efetuada pelos especialistas para os professores da escolarização básica? Deveríamos liberar os professores para a compra e adoção de qualquer material? Devemos reivindicar que os professores universitários se engajassem na produção de livros didáticos de história sistematicamente, como contribuição à melhoria da qualidade desse artefato?

Boa reflexão!

\section{Sobre 0 autor}

Itamar Freitas possui graduação em História pela Universidade Federal de Sergipe (UFS) (1996), especialização em Organização de Arquivos pela Universidade de São Paulo-USP (1997), mestrado em História Social pela Universidade Federal do Rio de Janeiro-UFRJ (2000), doutorado em Educação pela Pontifícia Universidade Católica de São Paulo-PUC-SP (2006) e desenvolve atividades de pós-doutorado no Programa de Pós-Graduação em História da Universidade de Brasília-PPGH/UnB (2013-2014). É professor do Departamento de Educação e do Núcleo de Pós-Graduação em Educação da Universidade Federal de Sergipe e tem experiência nas áreas de História e Educação, com ênfase em ensino de história, teoria da metodologia da história, história da historiografia e história do tempo presente. E-mail: itamarfo@gmail.com.

Artigo recebido em 08 de junho de 2014.

Aprovado em 10 de julho de 2014. 